\title{
Remazol Effluent Treatment in Batch and Packed Bed Column Using Biochar Derived from Marine Seaweeds
}

\author{
R. Gokulan*†, A. Vijaya Kumar*, V. Rajeshkumar** and S. Praveen*** \\ *Department of Civil Engineering, GMR Institute of Technology, Rajam-532 127, Andhra Pradesh, India \\ **Department of Civil Engineering, KPR Institute of Engineering and Technology, Arasur-641 407, Tamil Nadu, India \\ ***Department of Civil Engineering, Anna University, University College of Engineering, Ramanathapuram-623 513, \\ Tamil Nadu, India \\ †Corresponding author: R. Gokulan; gokulan.r@gmrit.edu.in
}

Nat. Env. \& Poll. Tech.

Website: www.neptjournal.com

Received: 23-01-2020

Revised: 21-02-2020

Accepted: 05-03-2020

Key Words:

Adsorption

Biochar

Elution

Seaweeds

Remazol effluent

\begin{abstract}
The release of textile effluents into the biosphere is a serious threat to the environment and promotes several health issues. Although several studies have been carried out in the remediation of textile effluents using adsorbents, the continuous mode of operation (packed bed) to treat effluent generated from the cotton-based textile industry using biosorbent is seldom reported. Here, one such investigation is made to remediate the Remazol effluent solution in batch and continuous mode of operation. A maximum decolourization efficiency of $77.5 \%$ and $49.66 \%$ was obtained for Ulva lactuca derived biochar in batch and continuous study. Column data parameters such as overall sorption time zone, breakthrough time, exhaustion time and volume of effluent treated were also calculated. Regeneration studies showed that $0.01 \mathrm{M}$ sodium hydroxide can be utilized for sorption-elution up to three regeneration cycles.
\end{abstract}

\section{INTRODUCTION}

Due to an increase in population and rapid industrialization, pollutants are becoming one of the emerging problems. Of the different resources, water is one of the important natural resources which is very essential for day to day activities in human life. But in recent years the water demand is continuously increasing because of groundwater depletion and surface water contamination. Surface water is polluted mainly due to industrial activities. These industries are not having effective treatment methods and in turn, discharging their pollutants directly into the nearby water bodies (Abdolali et al. 2014). This pollutant when mixed with the surface water, it affects the quality of the water and it is becoming unfit for domestic purpose. Even a very less concentration $(1 \mathrm{mg} / \mathrm{L})$ of pollutant if mixed with the water it will change the physical, chemical and biological characteristics of the water. If this water is consumed by the human it will result in many health issues like skin allergy, typhoid, fever, cholera, cancer, kidney failure, respiratory problems and several other health issues (Salleh et al. 2011). So, the effluent generated from the industry must be completely treated and then should be disposed to the nearby water bodies.

Many treatment methods are available for the removal of pollutants from the wastewater. These treatment methods are broadly classified as physical, chemical and biological (Robinson et al. 2001). Physical methods namely membrane filtration, adsorption, electrokinetic coagulation, ionexchange and irradiation are the commonly used methods for the removal of pollutants (Yagub et al. 2014). The chemical method used for the removal of pollutants from wastewater includes ozonation, oxidation and photochemical methods. The chemical method utilizes one form of chemical to convert the pollutants into another form. So chemical methods will produce secondary pollutants to the environment. In recent years, much research has been carried out using biological methods for the remediation of pollutants (Safa et al. 2011, Kaushik \& Malik 2009). These include biosorption, phytoremediation, bioventing, biodegradation, bioleaching bioaccumulation, bio-sparging, bio-augmentation and biostimulation. But biosorption is the mainly used biological methods for the remediation of pollutants. It involves the utilization of active or dead biomass for the remediation of the pollutants. Biosorption treatment is based on the combination of physical adsorption, micro-precipitation, ion exchange, and chelation process (Veglio \& Beolchini, 1997). The biosorbents are generally derived from bacteria, fungi, industrial wastes, agricultural wastes and seaweeds (Vijayaraghavan \& Yun 2008). 
In recent years biochar (a carbon-rich material produced in the absence of oxygen) is used for the biosorption process (Chen et al. 2019, Gunarathne et al. 2019). It is also reported that biochar, a green adsorbent is capable of remediating heavy metals (Sahmoune et al. 2019). In the past research, biochar has been effectively utilized for soil enrichment (Xu et al. 2018). But very limited work has been carried out for the utilization of biochar in the biosorption process. The current investigation is to produce biochar from green marine seaweeds. The utilization of these marine seaweeds will produce effective sorbent at very low cost or nil cost. These seaweeds are considered as a secondary pollutant to the environment since it affects the self-purification process and also it affects photosynthesis process of the water bodies (Zaharia et al. 2009). Textile industries are the fast-growing industries that use different types of dyes for colouring and utilize an enormous amount of water that leads to water pollution. The current investigation attempts the treatment of real Remazol effluent that is generated from cotton-based textile industries in batch and continuous mode of operation (packed bed). This is the first attempt made to produce biochar from marine seaweeds for the remediation of real Remazol effluent solution in batch and continuous process.

\section{MATERIALS AND METHODS}

\section{Seaweeds and Biochar Preparation}

Three green seaweeds (marine algae) namely Ulva lactuca, Ulva reticulata and Caulerpa scalpelliformis collected from Rameswaram (Tamilnadu, India) are used for the current investigation. The collected biomass was grounded and sieved to obtain a particle size of $0.75 \mathrm{~mm}$. A measured quantity of $50 \mathrm{~g}$ is taken and it is rinsed with deionized water and dried under natural conditions for 24 hours. Then the seaweeds are dried under $103^{\circ} \mathrm{C}$ for 12 hours to remove the moisture content present in the biomass. Now biochar is produced by thermal pyrolysis at $300^{\circ} \mathrm{C}$ under oxygen-free environment (Gokulan et al. 2019a).

\section{Preparation of Remazol Effluent}

The Remazol dyes and other analytical grade chemical agents used in the current investigation were procured from Sigma-Aldrich (India). Remazol effluent that is employed in the textile industry is prepared based on the composition suggested by Alaton et al. (2002a \& b). According to this, the effluent comprises of Remazol brilliant blue R (369 mg), Remazol brilliant orange 3R (6 mg), Remazol brilliant violet 5R (194 mg) and Remazol black B (768 g), sodium hydroxide (510 mg), sodium carbonate $(13000 \mathrm{mg})$, sodium chloride (41000 mg) and acetic acid (790 mg). To confirm the 100\% composition of the real Remazol effluent, the mixture was boiled for $180 \mathrm{~min}$ in deionized water. After cooling the effluent for $12 \mathrm{~h}$, the effluent characteristics such as $\mathrm{pH}$, initial colour and total dissolved solids were measured. The effluent $\mathrm{pH}$ was estimated to be 10.7 and effluent was purple, whereas total dissolved solids were determined to be $840 \mathrm{mg} / \mathrm{L}$. The absorbance of the Remazol effluent was measured at 579 nm using UV-vis spectrophotometer (Shimadzu UV-1800).

\section{Batch Experiments}

Batch studies were carried out to find the optimum parameters for the maximum dye removal and it is achieved by varying biochar dosage, $\mathrm{pH}$, temperature and initial concentration. A 0.25 -litre conical flask with an operating volume of 0.1 -litre was used for the batch studies. The equilibrium time for the batch study was fixed for 8 hours and the content of the conical flask was completely mixed by placing in in an orbital shaker which rotates at $160 \mathrm{rpm}$. A centrifuge with an operating speed of $3000 \mathrm{rpm}$ for 5 minutes was used to separate the supernatant and pellet and the dye concentration was measured using a spectrophotometer. Desorption study was carried out to find the reusability of the spent biochar and to find the regeneration cycles to which the biochar can efficiently has the sorption process. Based on the previous study $0.01 \mathrm{M}$ of Sodium Hydroxide is used as the elutant with an S/L ratio of 5 and the three sorption- elution cycle is carried out.

\section{Column Experiments}

A packed bed column setup is used to find the ability of the biochar to continuously remediate the effluent solution. The packed column is made up of acrylic glass with $19 \mathrm{~mm}$ as the internal diameter of $330 \mathrm{~mm}$ as the total height of the column. On the other hand, a stainless sieve of $0.5 \mathrm{~mm}$ was placed at the bottom of the column followed by glass wool. A $1.5 \mathrm{~mm}$ glass circular beads were positioned at a height of $20 \mathrm{~mm}$ from the base of the column to maintain a steady flow of the effluent solution into the column. The column data analysis is carried out and it is discussed in detail in our previous study (Gokulan et al. 2019b). The schematic presentation of the packed bed column is given in Fig. 1.

To examine the applicability of the sorbent in the real wastewater scheme, it is important to conduct continuousflow trials. So, a packed bed column was used to explore the possibility of the sorbent to remediate the Remazol effluent continuously. Packed bed column was found to be one of the best models to continuously remediate the effluent solution in real-time effluent treatment (El Messaoudi et al. 2016, Diniz et al. 2008, Barquilha et al. 2017). It was also reported that when compared to all other methods, the packed bed is having several advantages in effluent treatment (Vijayaraghavan \& Yun 2008, Chen et al. 2012). In the current investigation, 


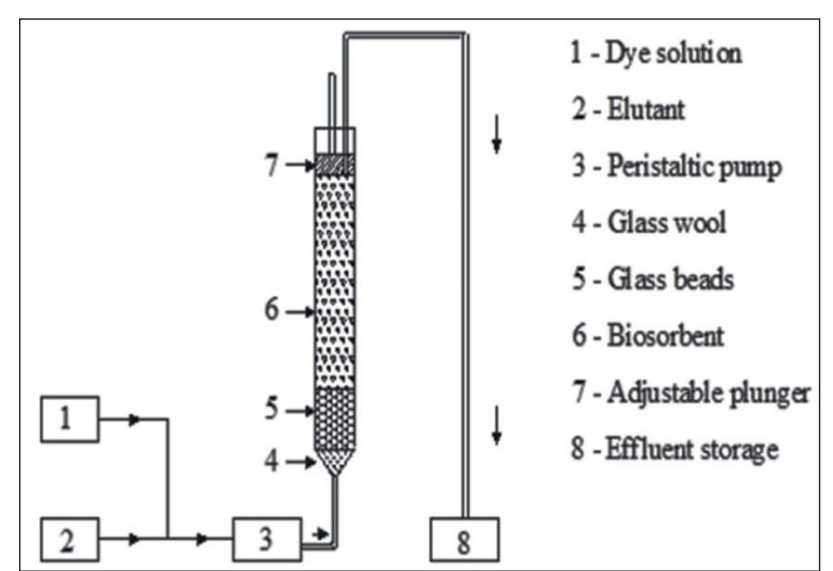

Fig.1: Packed bed for dye removal using biochar.

continuous trails were carried out by pumping the effluent solution from bottom to top and that allows the sorbent to be in contact with the sorbent where the sorption occurs. The exit effluent solution was collected and analysed for effluent concertation based on the absorbance value. The $\mathrm{S}$-shaped curve is obtained when a plot is done for time versus effluent concentration. This S-shaped curve is due to the mass transfer between the sorbent and the effluent (Hatzikioseyian et al. 2001). Based on the previous study, an up-flow packed column with the sorbent bed depth of 25 $\mathrm{cm}$ and a flow rate of $0.3 \mathrm{~L} / \mathrm{hr}$ was used for the continuous remediation of effluent solutions.

\section{RESULTS AND DISCUSSION}

\section{Batch Studies}

The batch study was carried out to find the optimum conditions for the maximum uptake capacity of the biochar and the maximum removal efficiency of different Remazol dyes with different biochar. The batch results indicated that that the optimum condition for all dye loaded biochar is dosage $2 \mathrm{~g} / \mathrm{L}, \mathrm{pH} 2$, temperature $30^{\circ} \mathrm{C}$ and initial concentration of $0.05 \mathrm{mmol} / \mathrm{L}$ with a contact time of 300 minutes (Gokulan et al. 2019c). These optimum conditions are used for the remediation of complex Remazol effluent solution in batch mode operation.

\section{Remazol Effluent Treatment in Batch Mode of Operation}

Effluent treatment studies are carried out to understand the potential of the adsorbent in the remediation of real-time effluent that is having industrial applications. In real dye effluents, along with the auxiliary chemicals, many other chemicals will be present and that is the biggest challenge for the sorbent in the remediation of the effluent solution. The influence of $\mathrm{pH}$ on the remediation of the Remazol effluent is studied and represented in Fig. 2a. Since Remazol effluent is complex with many dyes and other chemicals it is tough to express the concentration the effluent solution. So, the removal efficiency is calculated based on the absorbance value of the effluent solution and similar studies

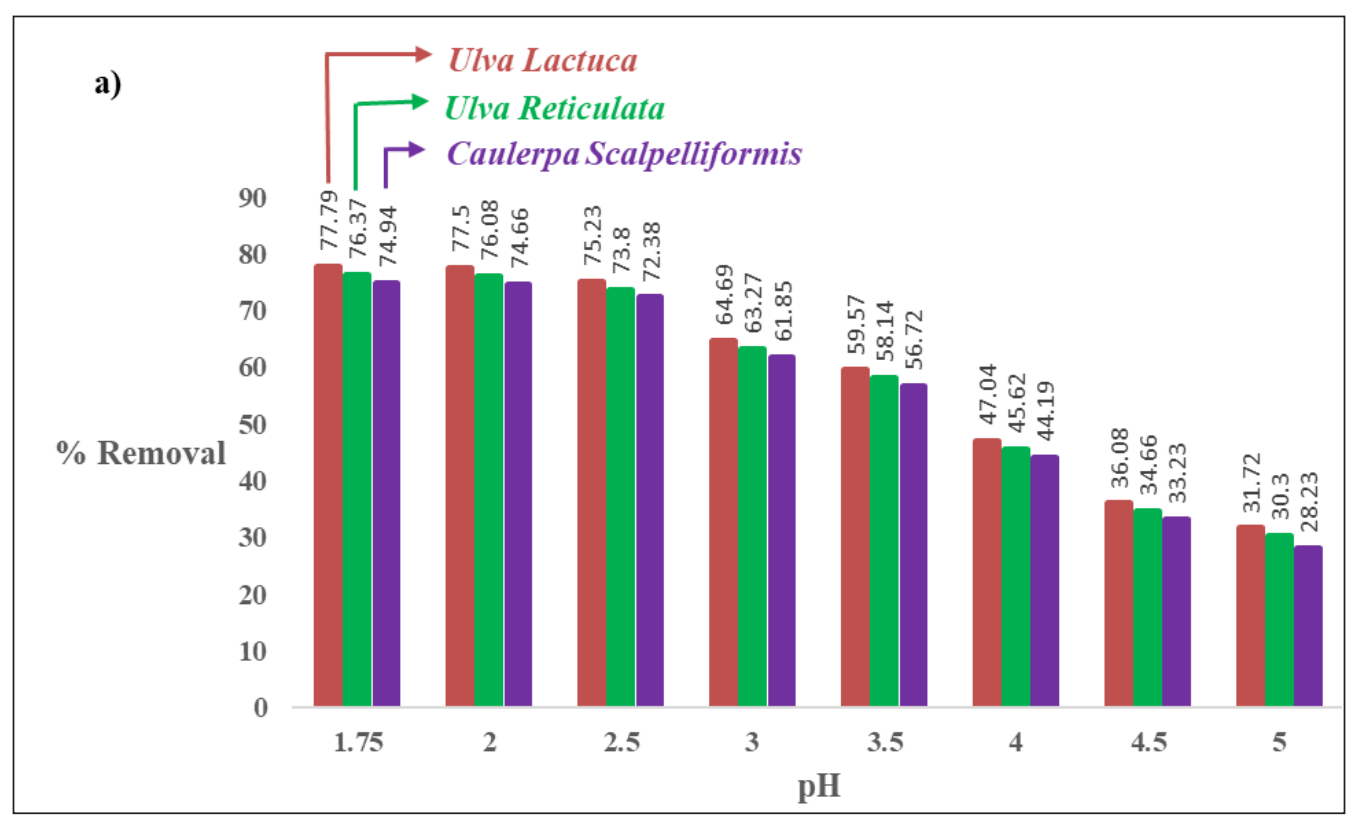




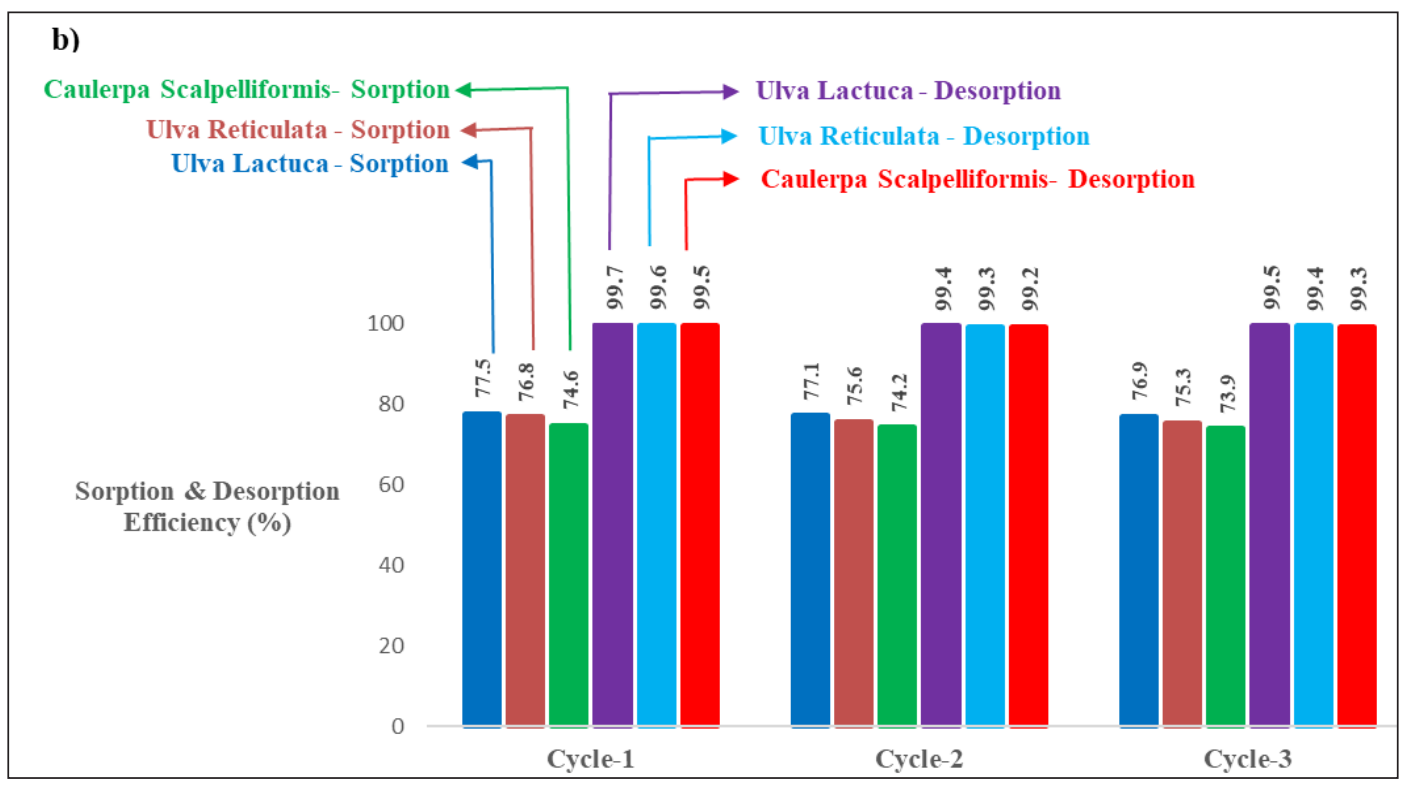

Fig. 2: a) Effect of $\mathrm{pH}$ on the sorption and b) Effect of sorption and desorption in regeneration cycles.

were carried out by many researchers (Alaton et al. 2002a, Vijayaraghavan et al. 2008a). The results showed that \% colour removal efficiency decreased with an increase in solution $\mathrm{pH}$. For instance, at $\mathrm{pH} 2.0$, U. lactuca, U. reticulata and C. scalpelliformis exhibited $77.5 \%, 76.8 \%, 74.6 \%$ removal efficiency compared to only $31.7 \%, 30.30 \%$ and $28.23 \%$ at $\mathrm{pH}$ 5.0. when compared to $\mathrm{pH} 2 . \%$ removal efficiency is more for $\mathrm{pH} 1.75$ but the difference in efficiency is less than $0.3 \%$ for all the concentrations of biochar. So, based on the economic aspect, $\mathrm{pH} 2$ can be considered as the optimum conditions for the maximum decolourization efficiency.

In the final set of effluent batch studies, the regeneration potential of different biochar towards remediation of Remazol effluent was attempted in successive three sorption-desorption cycles. Based on the previous batch studies $0.01 \mathrm{M}$ sodium hydroxide is considered as the best elutant for the regeneration studies. The results indicated that in all three sorption-elution cycles, sodium hydroxide exhibited a desorption efficiency higher than $99.5 \%, 99.4 \%, 99.3 \%$.

\section{Remazol Effluent Treatment in Continuous Mode of Operation}

The breakthrough curve obtained during remediation of Remazol dye effluent by different biochar is presented in Figs. $2 \mathrm{a}, 2 \mathrm{~b}$ and $2 \mathrm{c}$. The bed depth and flow rate were fixed at $25 \mathrm{~cm}$ and $0.3 \mathrm{~L} / \mathrm{h}$. The performance of biochar bed in the remediation of dye effluent was very good, with total dye decolourization efficiency of $49.66 \%, 48.86 \%$ and $47.93 \%$, with a column exhaustion time of 765,750 , and
735 minutes and breakthrough occurred at 120 minutes for biochar derived from Ulva lactuca, Ulva reticulata and Caulerpa scalpelliformis. Table 1 demonstrates the overall sorption zone, breakthrough time, exhaustion time and decolourization efficiency of the different biochar's. An effort has been made to regenerate the column bed using $0.01 \mathrm{M}$ sodium hydroxide at a flow rate of $0.6 \mathrm{~L} / \mathrm{h}$. Figs. $3 \mathrm{a}, 3 \mathrm{~b}$ and $3 \mathrm{c}$ explore the dye effluent elution curve, which increased sharply at the beginning and decreased gradually to reach equilibrium. The elution procedure produced a highly concentrated solution with elution efficiency of $99.14 \%$, $99.08 \%, 99.22 \%$.

\section{CONCLUSION}

Based on the experimental results the following observations were made:

- A maximum decolourization efficiency of $77.5 \%$, $76.08 \%, 74.68 \%$ for Ulva lactuca, Ulva reticulata, Caulerpa scalpelliformis is obtained at $\mathrm{pH} 2.0$, biochar dosage of $2 \mathrm{~g} / \mathrm{L}$, the temperature of $30^{\circ} \mathrm{C}$ and initial absorbance of 3.5125 .

- Desorption studies indicated that in all three sorptionelution cycles sodium hydroxide exhibited a desorption efficiency higher than $99.5 \%, 99.4 \%, 99.3 \%$.

- Continues studies reviled that the decolourization efficiency of $49.66 \%, 48.86 \%$ and $47.93 \%$ with a column exhaustion time of 765,750 , and 735 minutes is obtained for biochar derived from Ulva lactuca, Ulva reticulata and Caulerpa scalpelliformis 
Table 1: Column parameters for effluent treatment using different biochar.

\begin{tabular}{|llllll|}
\hline Biochar & $\begin{array}{l}\text { Breakthrough time } \\
\text { (hours) }\end{array}$ & $\begin{array}{l}\text { Exhaustion Time } \\
\text { (hours) }\end{array}$ & $\begin{array}{l}\text { Overall Sorption Zone } \\
\text { (hours) }\end{array}$ & $\begin{array}{l}\text { The volume of Effluent } \\
\text { treated (litres) }\end{array}$ & $\begin{array}{l}\text { Total dye } \\
\text { removal }(\%)\end{array}$ \\
\hline Ulva lactuca & 01 & 12.75 & 11.75 & 3.82 & 49.66 \\
Ulva reticulata & 01 & 12.50 & 11.50 & 3.75 & 48.86 \\
Caulerpa scalpelliformis & 01 & 12.25 & 11.25 & 3.67 \\
\hline
\end{tabular}
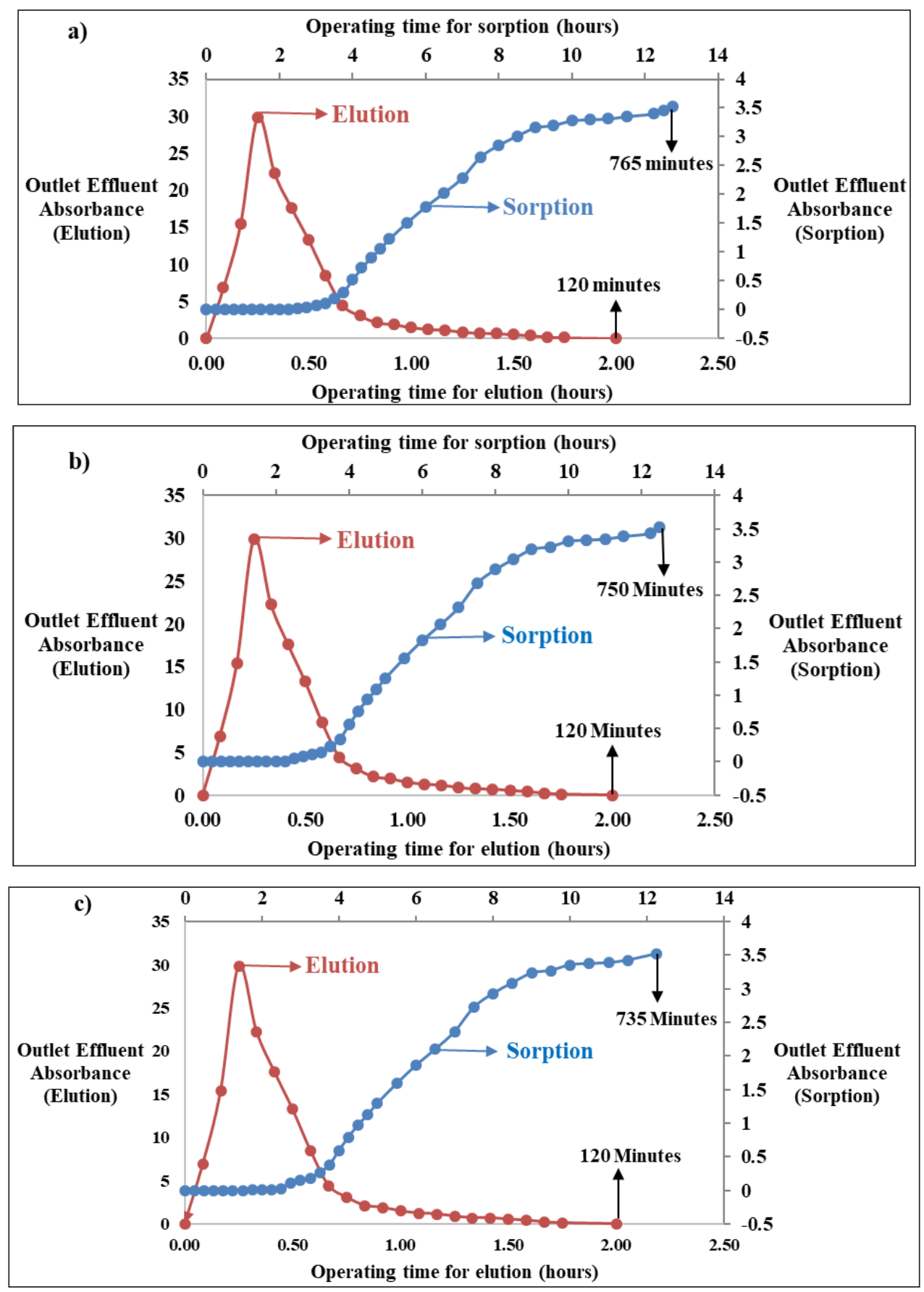

Fig. 3: Sorption and desorption of effluent by (a) Ulva Lactuca,(b) Ulva reticulata, and (c) Caulerpa scalpelliformis derived biochar. 
- Regeneration studies of the continues process explored that the elution has been completed within 120 minutes for all the biochar with elution efficiency of $99.14 \%$, $99.08 \%, 99.22 \%$.

\section{REFERENCES}

Abdolali, A., Guo, W.S., Ngo, H.H., Chen, S.S., Nguyen, N.C. and Tung, K.L. 2014. Typical lignocellulosic wastes and by-products for biosorption process in water and wastewater treatment: a critical review. Bioresour. Technol., 160:57-66. doi:10.1016/j.biortech.2013.12.037.

Alaton, I.A., Balcioglu, I.A. and Bahnemann, D.W. 2002a. Advance oxidation of a reactive dyebath effluent: comparison of $\mathrm{O}_{3}, \mathrm{H}_{2} \mathrm{O}_{2} / \mathrm{UV}-\mathrm{C}$ and $\mathrm{TiO}_{2} / \mathrm{UV}-\mathrm{A}$ processes. Water Res., 36: 1143-1154. doi: 10.1016/ S0043-1354(01)00335-9.

Alaton, I.A., Kornmuller, A. and Jekel, M. 2002b. Ozonation of spent reactive dye-baths: effect of $\mathrm{HCO}_{3}{ }^{-} / \mathrm{CO}_{3}{ }^{2-}$ alkalinity. J. Environ. Eng., 128: 689-696. doi: 10.1061/(ASCE)0733-9372(2002)128:8(689).

Barquilha, C.E.R., Cossich, E.S., Tavares, C.R.G. and Silva, E.A. 2017. Biosorption of nickel (II) and copper (II) ions in batch and fixed-bed columns by free and immobilized marine algae Sargassum sp. J. Clean. Prod., 150:58-64. doi: 10.1016/j.jclepro.2017.02.199

Chen, L., Li, F., Wei, Y., Li, G., Shen, K. and He, H.J. 2019. High cadmium adsorption on nanoscale zero-valent iron coated Eichhorniacrassipes biochar. Environ. Chem. Lett., 17: 589-594. doi:10.1007/s-10311 -0811-018y

Chen, S., Yue, Q., Gao, B., Li, Q., Xu, X. and Fu, K. 2012. Adsorption of hexavalent chromium from aqueous solution by modified corn stalk: a fixed-bed column study. Bioresour. Technol., 113: 114-120. doi: 10.1016/j.biortech.2011.11.110

Diniz, V., Weber, M.E., Volesky, B. and Naja, G. 2008. Column biosorption of lanthanum and europium by Sargassum. Water Res., 42: 363-371. doi: 10.1016/j.watres.2007.07.027

El-Messaoudi, N., Elkhomri, M., Dbik, A., Bentahar, S., Lacherai, A. and Bakiz, B. 2016. Biosorption of Congo red in a fixed-bed column from aqueous solution using jujube shell: Experimental and mathematical modelling. J. Environ. Chem. Eng., 4: 3848-3855. doi: 10.1016/j. jece.2016.08.027

Gokulan, R., Raja Murugadoss, J., Jegan, J. and Avinash, A. 2019c. Comparative desorption studies on remediation of remazol dyes using biochar (sorbent) derived from green marine seaweeds. Chemistryselect, 4: 7437-7445. doi: 10.1002/slct.201901348

Gokulan, R., Ganesh Prabhu, G. and Jegan, J. 2019b. A novel sorbent Ulva lactuca-derived biochar for remediation Remazol brilliant orange $3 \mathrm{R}$ in packed column. Water Environ. Res., 91: 642-649. doi: 10.1002/ wer. 1092

Gokulan, R., Ganesh Prabhu, G. and Jegan, J. 2019a. Remediation of complex remazol effluent using biochar derived from green seaweed biomass. Int. J. Phytoremediat., 21: 1179-1189. doi: 10.1080/15226514.2019.1612845

Gunarathne, V., Ashiq, A., Ramanayaka, S., Wijekoon, P. and Vithanage, M. 2019. Biochar from municipal solid waste for resource recovery and pollution remediation. Environ. Chem. Lett., 17: 12251235. doi:10.1007/s0-00866-019-10311

Hatzikioseyian, A., Tsezos, M. and Mavituna, F. 2001. Application of simplified rapid equilibrium models in simulating experimental breakthrough curves from fixed bed biosorption reactors. Hydrometallurgy, 59: 395-406. doi: 10.1016/S0304-386X(00)00169-9

Kaushik, P. and Malik, A. 2009. Fungal dye decolourization: Recent advances and future potential. Environ. Int., 35: 127-141. doi:10.1016/j. envint.2008.05.010

Robinson, T., McMullan, G., Marchant, R. and Nigam, P. 2001. Remediation of dyes in textile effluent: A critical review on current treatment technologies with a proposed alternative. Bioresour. Technol., 77: 247-255. doi:10.1016/S0960-8524(00)00080-8.

Safa, Y. Bhatti, H.N. Bhatti, I.A. and Asgher, M. 2011. Removal of direct Red-31 and direct Orange-26 by low cost rice husk: Influence of immobilisation and pre-treatments. Can. J. Chem. Eng., 89: 15541565 doi: $10.1002 /$ cjce. 20473

Sahmoune, M.N. 2019. Evaluation of thermodynamic parameters for adsorption of heavy metals by green adsorbents. Environ. Chem. Lett., 17: 697-704. doi:10.1007/s-00819-018-10311z

Salleh, M.A.M., Mahmoud, D.K., Karim, W.A.W.A. and Idris, A. 2011. Cationic and anionic dye adsorption by agricultural solid wastes: A comprehensive review. Desalination, 280: 1-13. doi:10.1016/j. desal.2011.07.019.

Veglio, F. and Beolchini, F. 1997. Removal of metals by biosorption: A review. Hydrometallurgy, 44: 301-316. doi: 10.1016/S0304386X(96)00059-X

Vijayaraghavan, K. and Yun, Y.S. 2008. Bacterial biosorbents and biosorption. Biotechnol. Adv., 26: 266-291. doi: 10.1016/j. biotechadv.2008.02.002

Vijayaraghavan, K. Lee, M.W. and Yun, Y.S. 2008a. A new approach to study the decolorization of complex reactive dye bath effluent by biosorption technique. Bioresour. Technol., 99:5778-5785. doi: 10.1016/j.biortech.2007.10.012.

Xu, M. Wu, J. Yang, G. Zhang, X. Peng, H. Yu, X. and Qi, H. 2018. Biochar addition to soil highly increases $P$ retention and decreases the risk of phosphate contamination of waters. Environ. Chem. Lett., 17:533541. doi:10.1007/s-0802-018-10311z

Yagub, M.T. Sen, T.K. Afroze, S. and Ang, H.M. 2014. Dye and its removal from aqueous solution by adsorption: A review. Adv. Colloid Interface. Sci., 209: 172-184. doi: 10.1016/j.cis.2014.04.002

Zaharia, C. Suteu, D. Muresan, A. Muresan, R. and Popescu A. 2009. Textile wastewater treatment by homogenous oxidation with hydrogen peroxide. Environ. Eng. Manag. J., 8:1359-1369. doi: 10.30638/eemj.2009.199. 